\title{
Travel to Tropical Countries: A Review of Travel-Related Infectious Diseases
}

Alwyn Rapose*

Consultant Infectious Diseases, Reliant Medical Group, University of Massachusetts, Worcester, MA, USA

\section{Introduction}

Fever or other symptoms in a patient returning from travel abroad have a broad differential diagnosis. Diseases endemic to the country of travel may include bacterial, viral and parasitic infections. Specialized travel clinics are able to provide information, counselling and prophylaxis against common infections seen in these countries. The aim of this paper is to highlight some of the most common travelassociated illnesses many of which can be prevented with appropriate vaccination and prophylactic medications.

\section{Case}

A 20-year-old female patient presented to an urgent care facility with fever for 3 days. The fever was as high as $104.5^{\circ} \mathrm{F}$. She also complained of intermittent abdominal pain and three loose stools on the day of presentation. She had recently returned from a twoweek family vacation to Bangladesh. None of the other members of the travel party were sick. Clinical examination was positive for fever and inconsistent areas of abdominal tenderness, without evidence of rebound, rigidity or organomegaly. There was no acute skin rash. Initial laboratory workup including complete blood count, comprehensive metabolic panel and urinalysis were normal. A peripheral blood smear was ordered, blood cultures were obtained, and the patient was discharged home. She returned with similar symptoms a few days later. This time her leucocyte count was down to $2.9 \times 10^{9} / 1$, hematocrit was 29.8 , platelet count was $120,000 / \mu \mathrm{l}$, peripheral smear was negative for parasites, alanine transaminase- $1986 \mathrm{u} / \mathrm{l}$, aspartate transaminase-1167 $\mathrm{u} / \mathrm{l}$ and blood cultures were growing gram-negative rods. With these findings she was admitted to the hospital and initiated on therapy with intravenous ceftriaxone. Blood cultures identified the organism as salmonella typhi. Stool cultures and serology were also positive for salmonella typhi. Serologies were negative for dengue fever, hepatitis A, B, C and HIV. Review of her medical records indicated that she had received the injectable typhoid vaccine prior to her previous trip to Bangladesh two years back. Since that trip had been uneventful for any infectious disease, she had decided not to take another typhoid vaccine prior to her most recent travel.

This case highlights many of the issues associated with travel to tropical countries. There is often a misconception about the need for travel counselling and vaccines, and most travelers do not feel the need to visit their physicians prior to travel to another country [1]. This may be especially true of persons travelling to their country of origin, visiting family and friends, or-as in the case reported above-those who are travelling back to a country they have visited before. "VFR"-visiting friends and relatives-is the term used for this group of travelers. This is not unique to the United States. Studies conducted in other developed countries have indicated similar findings [2-4]. Unfortunately even some developed countries have few specialized travel clinics and this definitely contributes to low utilization of vaccination and prevention services prior to travel [5].

The patient described above was ultimately diagnosed and treated for typhoid fever. However the differential diagnosis in this case included diseases such as viral infections hepatitis A and dengue fever, malaria, leishmaniasis and other insect-borne illnesses, and cholera and other food and water borne diseases.

\section{Travelers and risk of Infectious Diseases}

In 2011, more than 85 million international visits were made by United States citizens [6]. Travelers are at risk of being exposed to infections endemic in foreign countries, and they may also import these infections back to the United States. Persons making travel plans should be encouraged to visit a specialized travel clinic for information, counselling and prophylaxis against common infections seen in these countries. A study detailing demographics of travelers and health-care provided prior to international travel by a consortium of 18 United States travel clinics was published last year [7]. Literature indicates high quality care-in terms of appropriate recommendations-delivered by practices with physicians trained in travel medicine [8]. The visit to a travel clinic will also serve as a contact point to increase uptake of routine vaccines like influenza, pertussis and measles [9]. Counselling during this visit should include advice about preventive measures utilizing vaccines, prophylactic antimicrobials and strategies against mosquito-borne and food-borne diseases.

\section{Prophylactic Vaccines}

Vaccination against hepatitis A and typhoid are strongly recommended when travelling to all developing nations in the tropics. Both these infections are food and water-borne, sharing the same mode of transmission: the fecal-oral route.

\section{Hepatitis A}

Hepatitis A infection is considered one of the most common travel-associated infections that could be prevented with vaccination. Though rates of infection have dropped considerably with the introduction of effective vaccines, as well as improved sanitation and hygiene, risk persists for travelers to Africa, Asia and Latin America [10]. In the United States, the majority of new cases are associated with international travel [11].

The hepatitis A vaccine was first introduced in 1992, and was initially administered only to persons at risk for acquiring the infection. Universal vaccination against hepatitis A for children above the age of one year was recommended in the United States in May 2006 [12]. The hepatitis A vaccine is available in three forms. An inactivated vaccine (Havrix $^{\circledR}$-produced by GlaxoSmithKline and Vaqta ${ }^{\circledR}$ produced by

*Corresponding author: Alwyn Rapose, Consultant Infectious Diseases, Reliant Medical Group, University of Massachusetts, Worcester, MA, USA, E-mail: Alwyn.rapose@reliantmedicalgroup.org

Received January 22, 2013; Accepted June 20, 2013; Published June 26, 2013

Citation: Rapose A (2013) Travel to Tropical Countries: A Review of Travel-Related Infectious Diseases. Trop Med Surg 1: 128. doi:10.4172/2329-9088.1000128

Copyright: (c) 2013 Rapose A. This is an open-access article distributed under the terms of the Creative Commons Attribution License, which permits unrestricted use, distribution, and reproduction in any medium, provided the original author and source are credited. 
Merck \& Co., Inc.) is given in two doses 6 months apart. A second vaccine-hepatitis $\mathrm{A}$ in combination with hepatitis $\mathrm{B}$ (Twinrix ${ }^{\mathbb{B}}$ produced by GlaxoSmithKline) is given in three doses $(0,1$ and 6 months). A combined hepatitis A and typhoid vaccine (Hepatyrix ${ }^{\mathrm{TM}}$ produced by GlaxoSmithKline and Viatim ${ }^{\mathrm{TM}}$ produced by Sanofi Pasteur) is available in Europe. This is administered in two doses 6 months apart. Comparisons in effectiveness and tolerability have been studied by various groups [13-15]. No additional doses of hepatitis A vaccine are required for those who complete the initial series. As can be expected, the administration of combination vaccines-hence reducing the number of injections prior to travel-helps to make these recommended immunizations more acceptable.

\section{Typhoid}

Typhoid (enteric fever) has overtaken hepatitis $\mathrm{A}$ as the most common vaccine-preventable-disease in travelers. The majority of infections are acquired in Asia [16-18]. The history of typhoid vaccine research is very interesting. The first vaccines were developed as early as in the 1890's. Early vaccines had severe adverse effects. Safe vaccines are now available and on-going research involves investigations into increased efficacy of the vaccine [19].

In the United States, typhoid vaccine is available in two forms. An inactivated injectable vaccine (Typhim $\mathrm{Vi}$ ) is used in a single dose, approved for use after age 2 years. It requires subsequent doses after every two years for those who return to a country of risk. A live attenuated oral vaccine $\left(\right.$ Vivotif $\left.^{\mathbb{R}}\right)$ is approved for use after age 6 years. It is prescribed as one capsule on alternate days for four doses. This vaccine requires repeat dosing after five years in those who return to a country of risk. The live vaccine is contraindicated in those with an impaired immune system. These vaccines are considered safe, though protection is only around $70 \%$. Vaccination against typhoid should be completed at least 1 week prior to travel.

\section{Polio}

Polio is caused by an enterovirus transmitted by the fecal-oral route. The Global Polio Eradication Initiative (GPEI) and efforts of similar organizations have resulted in elimination of polio from Western Europe, the Americas and the majority of countries in Africa and Asia [20]. However, polio remains endemic in some tropical countries of Africa and Asia. Elimination has been unsuccessful in Pakistan, Afghanistan and Nigeria. In 2012, the total number of new polio cases reported globally was 222, of which 216 cases were reported from these three countries [20]. India-one of the common travel destinations for tourism and business-has not reported a new case for the last two years.

Two types of vaccines against polio are available, a live vaccine available in oral form (OPV), and an inactivated vaccine that is administered as an intramuscular injection (IPV). Only IPV is used in the United States. Adult who have received the primary polio vaccine series and travelling to countries endemic for polio, as well as their neighboring countries, are recommended a single booster dose of IPV prior to travel. An updated list of countries where booster dose is recommended prior to travel is available on the CDC website [21].

\section{Yellow Fever}

Yellow fever (YF) is a mosquito-borne viral infection endemic in tropical countries of Africa and South America. The majority of outbreaks previously occurred in West Africa, but more recently an increased number of cases are being reported from Central Africa. The latest outbreak in Darfur has resulted in 71 deaths among more than
800 suspected cases as reported by the Sudanese Ministry of Health and the WHO. In South America, YF is seen in the very rural areas of Peru and Bolivia. However, more recently, cases have been reported in urban areas including major tourist cities in Brazil. An updated summary of the epidemiology of YF and recommendations for YF vaccine-including countries where YF vaccination is recommended for travelers-is published by the Centers for Disease Control and Prevention (CDC) [22].

The YF vaccine is a live vaccine administered as a single intramuscular injection. $80 \%-100 \%$ individuals who receive the vaccine develop neutralizing antibodies [22]. The vaccine is ideally given at least 21 days prior to travel to risk area. Antibody response is delayed in older persons and risk for adverse events also increases with age $[23,24]$. Although antibodies have been detected even 19 years after initial vaccine, the vaccine is expected to provide protection for 10 years, after which a repeat vaccine is required for those returning to risk areas. As the YF vaccine is a live vaccine it is relatively contraindicated in persons with immune dysfunction and infants less than 6 months of age. Risks and benefits of vaccination in persons with HIV and pregnant females are discussed in detail in the CDC summary guidelines [22].

\section{Japanese Encephalitis}

Japanese Encephalitis (JE) is a mosquito-borne viral infection endemic in rural regions of Asia and the Western Pacific. First isolated in 1935, JE is considered the most common cause of vaccinepreventable-encephalitis in Asia [25]. In a study from Bangladesh, 3 out of 13 cases of viral meningo-encephalitis were attributed to JE [26]. Risk is expected mainly in rice and pig farming rural areas of these countries. A map of the geographic distribution of this infection as well as detailed information of each country regarding transmission season and region affected is available on the CDC website [25] Vaccination against JE is recommended for travelers to these endemic regions. Ixiaro ${ }^{\circledR}$ is an inactivated vaccine available in the United States. It is administered as two intramuscular injections 28 days apart. It is licensed for use in individuals aged 17 years and older, but clinical trials in pediatric populations indicate good safety profile [27]. A single booster dose one year after primary series is recommended for travelers returning to high risk areas. However if it has been more than two years since the primary series, the 2-dose series of the vaccine may be required for travelers returning to JE endemic areas.

\section{Meningitis}

Meningitis can be caused by a diverse group of microorganisms including bacteria and viruses. Also, "non-infectious" meningitis can be caused by a variety of chemicals including medications. Meningococcal meningitis is caused by the bacteria Neisseria meningitides and occurs world-wide. However, travelers to Africaespecially the "meningitis belt" of sub-Saharan Africa [28] and some countries in Asia are considered to be at high risk of contracting the infection and are recommended preventive vaccination prior to travel. Hajj pilgrims to Mecca and Medina in Saudi Arabia are also required to get meningitis vaccine. Transmission is person-to-person via respiratory secretions. There are five major serotypes of $N$. meningitides (A, B, C, Y and W-135) associated with the disease. Two quadrivalent conjugate vaccines (MCV4) are licensed to be used in the United States (Menactra by Sanofi Pasteur and Menveo by Novartis) and approved for use in persons aged 9 months to 55 years. A polysaccharide vaccine (MPSV4) (Menomune by Sanofi Pasteur) is also available. It is given to those above age 55 years and may also be given to anyone above age 2 years. The CDC recommends routine 2 -dose vaccination starting 
at age 11-12 years [29]. A booster dose is recommended every five years for individuals with certain medical conditions which place them at risk for meningococcal disease, as well as travelers to endemic regions. Presently available vaccines do not include the serotype "B" and research into development of vaccine against this serotype is in progress.

\section{Mosquito and Other Insect-Borne Illnesses}

Infections may be transmitted by the bites of mosquitoes, flies, fleas, ticks and other insects. Insect-borne infections seen in tropical countries include diseases like malaria, chikungunya, and dengue fever (mosquito), leishmaniasis (sand fly), trypanosomiasis (tsetse fly) and onchocerciasis (black fly). Prophylactic antimicrobials are available against malaria, but not against most of the other insect-borne diseases seen in tropical countries. Hence proper protection against insect exposure is very important. Sprays or creams containing DEET (n,ndiethyl-meta-toluamide) are available for use on the skin and also on clothing. The CDC recommends the use of 30\% DEET for protection against mosquito and other insect bites [30]. DEET should not be used in infants less than 2 months of age. Covering the skin with protective clothing, using mosquito nets on beds, use of insect repellant aromas or vaporizing mats and other methods are strongly recommended. Clothing and mosquito nets can be treated with permethrin to increase protection. Using closed footwear when travelling through jungles or marshlands is essential to protect the traveler from parasites that can enter through the skin. Swimming in fresh-water should be avoided in remote areas to protect against "river flukes".

\section{Malaria}

Malaria is caused by infection with the parasite plasmodium transmitted to humans by the bite of an infected mosquito. It is endemic in many tropical countries. There are five major species of plasmodium that can infect humans. In 2010 an estimated 219 million cases, with 660,000 deaths due to malaria were reported in an updated version of the "World Malaria Report". As many as $40 \%$ of these cases were reported from just three countries-The Democratic Republic of Congo, Nigeria and India [31]. The most recently identified species plasmodium knowlesi has probably been prevalent at low levels in Southeast Asia for several years and is responsible for an increased number of cases of malaria in Malaysia in recent years $[32,33]$. Distinguishing it morphologically from plasmodium malariae is difficult and diagnosis requires pcr testing. Uncomplicated cases can be treated with chloroquin, while more severe cases require intravenous artenusate [33]. The majority of cases seen in the United States are in persons returning from travel to a malaria-endemic region [34]. The most important aspect of malaria prevention in travelers is prevention of mosquito bites and use of prophylactic antimalarial pills (chemoprophylaxis). In a study published in 2012, the CDC reported that of the patients in the United States diagnosed with malaria on return from travel, only $25 \%$ had taken chemoprophylaxis [34]. Chloroquine, doxycycline, mefloquine and malarone are the four medications most commonly used in the United States for malaria chemoprophylaxis. A detailed guide regarding the species of plasmodium and the medications recommended when travelling is available at the CDC website [35]. The choice of the medication depends on the country of travel (plasmodium species and resistance pattern in that country), the traveler's underlying medical conditions and lastly-patient's personal preferences.

Chloroquine is given as a single tablet to be taken once a week. Prophylaxis is initiated one week prior to travel, continued once a week throughout the travel and then once a week for four weeks after leaving the malaria-risk area. Unfortunately, chloroquine resistance is seen in most countries of Africa and Asia, as well as in some countries in South America. The evolution of chloroquine resistance and the emergence of highly resistant malaria at the "epicenter of drug resistance"-the Thailand-Cambodia border-has been elegantly reviewed by Mita and Tanabe [36]. Mefloquine, malarone or doxycycline are available for use when travelling to countries with chloroquine-resistant malaria. Mefloquine dosing is similar to that of chloroquine. It is avoided in persons with history of psychiatric illness and seizure disorders. Mefloquine resistance is seen in some countries in South-East Asia. Malarone is a combination medication (atovaquone with proguanil). It is dosed as a single tablet to be taken once a day. Prophylaxis should be initiated 2 days prior to arrival in the endemic country, continued daily while in the endemic area and then for one week after return from the malaria-risk area. It is contraindicated in pregnancy and in patients with kidney disease. The dosing of chloroquine, mefloquine and malarone has to be adjusted according to body weight when prescribed for children. Doxycycline is recommended in a dose of one tablet daily, to be initiated 2 days prior to arrival in the endemic area, continued daily while in the endemic area and then for four weeks after return. It is contraindicated in children and in pregnancy. It is the least expensive of the medications prescribed for malaria prophylaxis.

Malarone was the most commonly prescribed agent in the patients evaluated by the Global TravEpiNet [7] and the authors questioned the overuse of this expensive agent. This could be secondary to patients' (or physicians') fear of neuropsychiatric symptoms reported with mefloquine. In a randomized double-blind study comparing mefloquine versus malarone, efficacy and number of adverse events were comparable, though discontinuation rates were higher for mefloquine [37]. In a study from Switzerland involving more than 1000 travelers, authors reported that $45 \%$ travelers chose mefloquine, $21 \%$ chose malarone and $18 \%$ chose doxycycline. Patients were given colored tables with data comparing the three medications with regards to the dosing regimen, nature and rates of adverse events, efficacy and price. The authors concluded that more patients chose mefloquine when they were given objective information about the different agents available for malaria chemoprophylaxis [38]. Mefloquine was also the most commonly used agent reported in the CDC's 2010 Malaria Surveillance Summary [34].

Efforts to reduce the world-wide disease burden include research towards development of safe and effective malaria vaccines. Modest efficacy with the candidate vaccines-RTS, S/AS01 (33\%) in a phase 3 trial, [39] and RTS,S/AS02 (50\%) in a phase 2b trial in Tanzania [40] are encouraging.

\section{Dengue}

Dengue is a viral infection transmitted to humans by the bite of an infected Aedes mosquito. It is endemic in many tropical countries of Southeast Asia, some popular tourist destinations in South America and Puerto Rico, with almost a million new infections every year [41]. The World Health Organization considers dengue the most important arthropod-borne viral infections in humans. There are a number of candidate vaccines under investigations [42]. Unfortunately, no vaccines are currently available for routine use. Hence travelers are recommended wearing clothing that covers most of the skin especially during the day when the mosquitoes are most active, as well as using DEET on exposed skin as well as clothing. 
Citation: Rapose A (2013) Travel to Tropical Countries: A Review of Travel-Related Infectious Diseases. Trop Med Surg 1: 128. doi:10.4172/ 2329-9088.1000128

Page 4 of 5

\begin{tabular}{|c|c|c|c|c|}
\hline Vaccine & Age & Doses & Administration & Protection \\
\hline Hepatitis A & After age 1 year & 2 doses $6-12$ months apart & $\begin{array}{l}\text { Anytime, but best } 2 \text { weeks before } \\
\text { departure }\end{array}$ & $\begin{array}{l}2 \text { doses are considered to provide } \\
\text { life-long protection }\end{array}$ \\
\hline Typhoid-IM & After age 2 years & 1 dose & 2 weeks before departure & 2 years \\
\hline -oral & After age 6 years & $\begin{array}{l}1 \text { capsule every alternate day for } 4 \\
\text { doses }\end{array}$ & $\begin{array}{l}\text { Complete } 4^{\text {th }} \text { dose } 1 \text { week before } \\
\text { departure }\end{array}$ & 5 years \\
\hline Polio & Adults & $\begin{array}{l}1 \text { dose in those who have completed } \\
\text { primary series in childhood }\end{array}$ & Anytime before departure & Life-long \\
\hline Yellow Fever & After age 9 months & 1 dose & $\begin{array}{l}\text { Anytime, ideally } 21 \text { days before } \\
\text { departure }\end{array}$ & 10 years \\
\hline Japanese encephalitis & After age 17 years & 2 doses 28 days apart & $\begin{array}{l}\text { Complete } 2^{\text {nd }} \text { dose } 1 \text { week before } \\
\text { departure }\end{array}$ & $1-2$ years \\
\hline Meningitis -MCV4 & After age 9 months & 1 dose & Anytime before departure & 5 years \\
\hline MPSV4 & After age 2 years & 1 dose & Anytime before departure & 5 years \\
\hline
\end{tabular}

Table 1: Travel Vaccines with information about age restrictions, optimal time for administration prior to travel, dosing and duration of protection.

\section{Diarrheal Illness and Food and Water-Borne Diseases}

Many studies summarizing illnesses in persons returning home from travel abroad report that diarrhea and other gastrointestinal problems are the most common symptoms [43-45]. Travelers' Diarrhea (TD) is a non-specific term and may include infectious and noninfectious causes of loose stools in a person returning from travel to another country. A very short episode of watery diarrhea may be caused by intolerance to a food or spice, while infectious causes of diarrhea may be bacterial, viral or parasitic. It is very difficult to anticipate the cause of TD. All travelers should be advised about proper hand-hygiene as well as food and water precautions. In general, hot cooked food and sealed bottled liquids should be advised. Some of the most common bacterial pathogens associated with TD include campylobacter, salmonella, shigella and escherichia coli $[46,47]$. Travelers are advised to carry with them a fluoroquinolone antibiotic (ciprofloxacin) in case they develop severe diarrhea. Quinolones are contra-indicated in pregnancy, and quinolone- resistant campylobacter and other infections are prevalent in some countries especially in South Asia [47]. Azithromycin is recommended as an alternative antibiotic [48]. Rifaximin which acts locally in the gastrointestinal tract without systemic absorption can also be used [49]. Cholera is endemic in some African and Asian tropical countries and outbreaks have occurred in non-endemic areas after natural disasters as seen in Haiti [50]. Unfortunately no effective vaccine is available in the United States. Volunteers and other travelers to these areas should strictly adhere to food and water hygiene. All travelers should be advised to report to their physicians on their return home if they experienced diarrhea during travel or shortly after their return. Stool tests may be indicated to look for gastrointestinal parasites seen in tropical countries (Table 1).

Research into vaccines for various gastrointestinal bacteria, viruses and parasites is on-going, but no vaccines are available for routine use.

\section{Other Infections}

Exotic infections seen as outbreaks in remote areas of tropical countries in Africa like Ebola (Congo, Uganda), Rift Valley Fever (Kenya, Somalia, South Africa), as well as other diseases associated with animal, reptile, spider or scorpion bites are beyond the scope of this review. Vaccine research is on-going, but no effective and safe vaccines have been licensed for human use. Suffice to say that use of insect repellants, appropriate travel gear and utilization of the services of qualified and experienced travel guides is imperative when travelling to very remote or jungle areas.

\section{Summary}

There is a wide spectrum of infectious diseases that a traveler may be exposed to on a trip to a tropical country. Unfortunately, the majority of travelers fail to utilize the services of specialized travel clinics. While a visit to a travel clinic does not guarantee an infection-free travel, advice regarding protection from diarrheal diseases, as well as mosquito and other insect-borne diseases goes a long way in reducing the risk of these infections. Safe and effective vaccines against a wide variety of infectious agents seen in tropical countries are also available. These should be strongly encouraged. In addition, the majority of cases of malaria in the United States occur in individuals returning from travel abroad. Appropriate malaria chemoprophylaxis should be emphasized for all travelers. The visit to a travel clinic also serves as an opportunity to update routine vaccines like measles, pertussis and influenza for individuals who may have missed recommended vaccine series.

\section{References}

1. Baggett HC, Graham S, Kozarsky PE, Gallagher N, Blumensaadt S, et al. (2009) Pretravel health preparation among US residents traveling to India to VFRs: importance of ethnicity in defining VFRs. J Travel Med 16: 112-118.

2. Heywood $A E$, Watkins RE, lamsirithaworn $S$, Nilvarangkul $K$, Macintyre $C R$ (2012) A cross-sectional study of pre-travel health-seeking practices among travelers departing Sydney and Bangkok airports. BMC Public Health 12: 321.

3. Zwar N, Streeton CL; Travel Health Advisory Group (2007) Pretravel advice and hepatitis A immunization among Australian travelers. J Travel Med 14: 31-36.

4. Van Herck K, Van Damme P, Castelli F, Zuckerman J, Nothdurft H, et al. (2004) Knowledge, attitudes and practices in travel-related infectious diseases: the European airport survey. J Travel Med 11: 3-8.

5. Namikawa K, lida T, Ouchi K, Kimura M (2010) Knowledge, attitudes, and practices of Japanese travelers on infectious disease risks and immunization uptake. J Travel Med 17: 171-175.

6. International Trade Administration, Office of Travel and Tourism. Available at http://tinet.ita.doc.gov/view/m-2011-O-001/index.html. Accessed January 12, 2013

7. LaRocque RC, Rao SR, Lee J, Global TravEpiNet: a national consortium of clinics providing care to international travelers--analysis of demographic characteristics, travel destinations, and pretravel healthcare of high-risk US international travelers, 2009-2011. Clin Infect Dis. 2012 Feb 15; 54(4):455-62.

8. Bouldouyre MA, De Verdière NC, Pavie J, De Castro N, Ponscarme D, et al. (2012) Quality of travel health advice in a French travel medicine and vaccine center: a prospective observational study. J Travel Med 19: 76-83.

9. Rapose A. Re-Emerging Infectious Diseases: Need for Improving Uptake of Existing Vaccines. J Vaccines Vaccin 2012, 3:6. doi:10.4172/2157$7560.1000 \mathrm{e} 111$.

10. Mutsch M, Spicher VM, Gut C, Steffen R (2006) Hepatitis A virus infections in travelers, 1988-2004. Clin Infect Dis 42: 490-497.

11. Klevens RM, Miller JT, Iqbal K, Thomas A, Rizzo EM, et al. (2010) The evolving epidemiology of hepatitis a in the United States: incidence and molecular epidemiology from population-based surveillance, 2005-2007. Arch Intern Med 170: $1811-1818$ 
Citation: Rapose A (2013) Travel to Tropical Countries: A Review of Travel-Related Infectious Diseases. Trop Med Surg 1: 128. doi:10.4172/ 2329-9088.1000128

Page 5 of 5

12. Available at: http://www.cdc.gov/mmwr/PDF/rr/rr5507.pdf. Accessed January 11, 2013.

13. Overbosch D, Peyron F, Picot N, Varichon JP, Dumas R, et al. (2005) Combined typhoid fever and hepatitis A vaccine: comparison of immunogenicity and safety to concomitant monovalent vaccine over 3 years. J Travel Med 12: 319-326.

14. Loebermann $\mathrm{M}$, Kollaritsch $\mathrm{H}$, Ziegler $\mathrm{T}$, Rendi-Wagner $\mathrm{P}$, Chambonneau $L$, et al. (2004) A randomized, open-label study of the immunogenicity and reactogenicity of three lots of a combined typhoid fever/hepatitis A vaccine in healthy adults. Clin Ther 26: 1084-1091.

15. Beeching NJ, Clarke PD, Kitchin NR, Pirmohamed J, Veitch K, et al. (2004) Comparison of two combined vaccines against typhoid fever and hepatitis $\mathrm{A}$ in healthy adults. Vaccine 23: 29-35

16. Boggild AK, Castelli F, Gautret P, Torresi J, von Sonnenburg F, et al. (2010) Vaccine preventable diseases in returned international travelers: results from the GeoSentinel Surveillance Network. Vaccine 28: 7389-7395.

17. Freedman DO, Weld LH, Kozarsky PE, Fisk T, Robins R, et al. (2006) Spectrum of disease and relation to place of exposure among ill returned travelers. N Eng J Med 354: 119-130.

18. Patel TA, Armstrong M, Morris-Jones SD, Wright SG, Doherty T (2010) Imported enteric fever: case series from the hospital for tropical diseases London, United Kingdom. Am J Trop Med Hyg 82: 1121-1126.

19. Marathe SA, Lahiri A, Negi VD, Chakravortty D (2012) Typhoid fever \& vaccine development: a partially answered question. Indian J Med Res 135: 161-169.

20. Global Polio Eradiation Initiative. Available at: www.polioeradication.org Accessed January 14, 2013.

21. CDC-Travel Health. Available at: http://wwwnc.cdc.gov/travel/notices/in-thenews/polio-outbreaks.htm. Accessed January 14, 2013

22. Staples JE, Gershman M, Fischer M; Centers for Disease Control and Prevention (CDC). Yellow fever vaccine: recommendations of the Advisory Committee on Immunization Practices (ACIP). MMWR Recomm Rep. $2010 \mathrm{Ju}$ 30; 59(RR-7): 1-27.

23. Roukens $A H$, Soonawala D, Joosten SA, de Visser AW, Jiang $X$, et al. (2011) Elderly subjects have a delayed antibody response and prolonged viraemia following yellow fever vaccination: a prospective controlled cohort study. PLoS One 6: e27753.

24. Martin M, Weld LH, Tsai TF, Mootrey GT, Chen RT, et al. (2001) Advanced age a risk factor for illness temporally associated with yellow fever vaccination. Emerg Infect Dis 7: 945-951.

25. CDC-Travel Health. Available at: http://wwwnc.cdc.gov/travel/yellowbook/2012 chapter-3-infectious-diseases-related-to-travel/japanese-encephalitis. htm\#1938. Accessed January 14, 2013.

26. Rasul CH, Muhammad F, Hossain MJ, Ahmed KU, Rahman M (2012) Acute meningoencephalitis in hospitalised children in southern Bangladesh. Malays J Med Sci 19: 67-73.

27. Dubischar-Kastner K, Kanesa-Thasan N (2012) Vaccinating against Japanese encephalitis virus: what have we learned from recent clinical trials? Expert Rev Vaccines 11: 1159-1161.

28. CDC-Travel Health.Available at: http://wwwnc.cdc.gov/travel/yellowbook/2012/ chapter-3-infectious-diseases-related-to-travel/meningococcal-disease.htm. Accessed January 14, 2013.

29. Updated recommendations for Use of Meningococcal Conjugate Vaccines. MMWR January28, 2011. Available at http://www.cdc.gov/mmwr/preview/ mmwrhtml/mm6003a3.htm. Accessed January 14, 2013.

30. CDC ATSDR-DEET-Guidelines to reduce exposure. Available at http://www. atsdr.cdc.gov/consultations/deet/guidelines.html Accessed January 14, 2013

31. World Malaria Report 2012. Available at: http://www.who.int/malaria/ publications/world malaria report 2012/wmr2012 full report.pdf. Accessed January 15, 2013.

32. William T, Rahman HA, Jelip J, Ibrahim MY, Menon J, et al. (2013) Increasing incidence of Plasmodium knowlesi malaria following control of P. falciparum and P. vivax Malaria in Sabah, Malaysia. PLoS Negl Trop Dis 7: e2026.

33. Rajahram GS, Barber BE, William T, Menon J, Anstey NM, et al. (2012) Deaths due to Plasmodium knowlesi malaria in Sabah, Malaysia: association with reporting as Plasmodium malariae and delayed parenteral artesunate. Mala J 11: 284.

34. Mali S, Kachur SP, Arguin PM; Division of Parasitic Diseases and Malaria Center for Global Health; Centers for Disease Control and Prevention (CDC) (2012) Malaria surveillance--United States, 2010. MMWR Surveill Summ 61 : $1-17$.

35. CDC Malaria Information and Prophylaxis. Available at http://www.cdc.gov/ malaria/travelers/country_table/a.html. Accessed January 14, 2013.

36. Mita T, Tanabe K (2012) Evolution of Plasmodium falciparum drug resistance: implications for the development and containment of artemisinin resistance. Jpn J Infect Dis 65: 465-475.

37. Overbosch D, Schilthuis H, Bienzle U, Behrens RH, Kain KC, et al. (2001) Atovaquone-proguanil versus mefloquine for malaria prophylaxis in nonimmune travelers: results from a randomized, double-blind study. Clin Infect Dis 33 . 1015-1021.

38. Senn N, D'Acremont V, Landry P, Genton B (2007) Malaria chemoprophylaxis: what do the travelers choose, and how does pretravel consultation influence their final decision. Am J Trop Med Hyg 77: 1010-1014.

39. RTS,S Clinical Trials Partnership, Agnandji ST, Lell B, Fernandes JF, et al. (2012) A phase 3 trial of RTS,S/AS01 malaria vaccine in African infants. N Engl J Med 367: 2284-2295.

40. Abdulla S, Salim N, Machera F, Kamata R, Juma O, et al. (2013) Randomized controlled trial of the long term safety, immunogenicity and efficacy of RTS,S/ AS02(D) malaria vaccine in infants living in a malaria-endemic region. Mala J 12: 11 .

41. Li Z, Sakota V, Jackson D, Franklin AR, Beall B; Active Bacterial Core Surveillance/Emerging Infections Program Network (2003) Array of M protein gene subtypes in 1064 recent invasive group A streptococcus isolates recovered from the active bacterial core surveillance. J Infect Dis 188: 1587-1592.

42. Wan SW, Lin CF, Wang S, Chen YH, Yeh TM, et al. (2013) Current progress in dengue vaccines. J Biomed Sci 20: 37.

43. Lim PL, Han P, Chen LH, MacDonald S, Pandey P, et al. (2012) Expatriates ill after travel: results from the Geosentinel Surveillance Network. BMC Infect Dis 12: 386

44. Hagmann S, Neugebauer R, Schwartz E, Perret C, Castelli F, et al. (2010) Illness in children after international travel: analysis from the GeoSentinel Surveillance Network. Pediatrics 125: e1072-e1080.

45. Hunziker T, Berger C, Staubli G, Tschopp A, Weber R, et al. (2012) Profile of travel-associated illness in children, Zürich, Switzerland. J Travel Med 19: 158-162.

46. Kendall ME, Crim S, Fullerton K, Han PV, Cronquist AB, et al. (2012) Travelassociated enteric infections diagnosed after return to the United States, Foodborne Diseases Active Surveillance Network (FoodNet), 2004-2009. Clin Infect Dis 54 Suppl 5: S480-S487.

47. Ouyang-Latimer J, Jafri S, VanTassel A In vitro antimicrobial susceptibility of bacterial enteropathogens isolated from international travelers to Mexico, Guatemala, and India from 2006 to 2008. Antimicrob Agents Chemother. 2011 Feb; 55(2): 874-8

48. Serichantalergs O, Dalsgaard A, Bodhidatta L, Krasaesub S, Pitarangsi C, et al (2007) Emerging fluoroquinolone and macrolide resistance of Campylobacter jejuni and Campylobacter coli isolates and their serotypes in Thai children from 1991 to 2000. Epidemiol Infect 135: 1299-1306.

49. Alajbegovic S, Sanders JW, Atherly DE, Riddle MS (2012) Effectiveness of rifaximin and fluoroquinolones in preventing travelers' diarrhea (TD): a systematic review and meta-analysis. Syst Rev 1: 39.

50. Centers for Disease Control and Prevention (CDC) (2010) Update on cholera --- Haiti, Dominican Republic, and Florida, 2010. MMWR Morb Mortal Wkly Rep 59: 1637-1641. 